\title{
Diagnosis and treatment planning for primary molar ankylosis along with unerupted maxillary premolar: Case report
}

\author{
Mario Cappellette Jr ${ }^{*}$, Fauze Ramez Badreddine ${ }^{2}$, Fabio Eduardo Maiello Monteiro Alves ${ }^{3}$ and Lucia Hatsue Yamamoto Nagai ${ }^{4}$ \\ ${ }^{1}$ Department of Otolaryngology-Head and Neck Surgery, Discipline of Pediatric Otolaryngology, Universidade Federal de São Paulo-UNIFESP/Escola, Paulista \\ de Medicina EPM, São Paulo, Brazil \\ ${ }^{2}$ Orthodontist, Brazilian Association of Dentistry, São Paulo, Brazil \\ ${ }^{3}$ Postgraduate student, Division of Pediatric Otolaryngology, Department of Otolaryngology, Head and Neck Surgery, Federal University of São Paulo, São Paulo, \\ Brazil \\ ${ }^{4}$ Orthodontist, Brazilian Association of Dentistry, São Paulo, Brazil
}

\begin{abstract}
Background: Dentoalveolar ankyloses of the deciduous tooth may lead to collapse of the dental arch complicating eruption and development of the succedaneous permanent dentition. The early interceptive orthodontic treatment is recommended to avoid complications on the eruptive process of the successor tooth.

Objective: The aim of this article is to report the orthodontic treatment of a patient with ankylosed maxillary deciduous molar along with unerupted both maxillary second permanent premolars.

Materials and methods: A 15-year-old female patient presented with a complaint about severely intruded maxillary left second deciduous molar and inclination of the adjacent tooth. Computed tomography scam (CT) showed that the premolars were found to be ankylosed and were extracted. The extraction spaces were closed by moving the posterior teeth mesially through $\mathrm{NiTi}$ closed springs with miniscrew anchorage.

Results: In the maxillary arch, the first molars were positioned in the place of the second premolars. The occlusal posttreatment evaluation revealed a Class II molar and Class I canine relationship on both sides, normal overjet and overbite, and good intercuspation. Ideal functional occlusion was obtained. Panoramic radiography revealed good positioning and good periodontal health of the teeth, and the parallax of the roots of the teeth. the patient's skeletal pattern was not altered by the mechanics and the facial esthetics was not compromised
\end{abstract}

Conclusion: It is important to diagnose the dental ankyloses or impaction problems as early as possible in order to treatment planning achieve better results along stability in long-term.

\section{Introduction and background}

A favorable sequence of tooth eruption can be broken by a disturbance in the mixed dentition period leading to permanent tooth impaction [1]. Studies have related that the prevalence of impacted or unerupted premolars rank third in frequency after third molars and maxillary canines $[2,3]$. The prevalence of impacted premolars has been varied according to age $[3,4]$. The overall prevalence in adults has been reported to be $0.5 \%$ with a range is $0.1 \%$ to $0.3 \%$ for maxillary premolars and $0.2 \%$ to $0.3 \%$ for mandibular premolars $[3,5]$.

Tooth impaction refers to tooth that fail to erupt [5-7] whose etiological factors may involve arch length deficiency, mechanical blockage, ectopic positioning, malformed teeth, trauma, systemic diseases, and over-retention of primary teeth or ankylosed primary teeth $[2,8]$.

Dentoalveolar ankylosis is an eruption anomaly defined as the union of the tooth root to the surrounding bone [2,8-15] with local elimination of the periodontal ligament and it may impede the normal development of teeth $[14,16]$. The affected teeth are usually deciduous molars with the condition affecting the mandibular second molar most often and the maxillary first molar least often [17]. The etiology of this condition is still not well-defined $[6,11,14,17-21]$ and there is a debate due to the lack of knowledge about its biological mechanisms [22]. It is associated with trauma $[9,23]$, metabolic disorders $[9,23]$, developmental disturbance [24], genetic tendency [8], and a deficiency in vertical-bone growth [10]. A higher incidence occurs at the molar region during the deciduous and mixed dentition [15]. The incidence of deciduous-tooth dentoalveolar ankylosis was reported to be $1.5 \%$ to $9.9 \%$ [15].

Diagnosis of dental ankylosis is generally established through clinical findings in which include metallic sounds upon percussion, lack of tooth mobility, and dental infraocclusion. However, some patients

Correspondence to: Mario Cappellette Jr, D.D., Ph.D., Department of Otolaryngology-Head and Neck Surgery, Discipline of Pediatric Otolaryngology, Universidade Federal de São Paulo-UNIFESP/Escola Paulista de Medicina EPM, São Paulo, Brazil; Tel: 5511999784798; E-mail: mjrcappellette@terra.com.br

Key words: submerged deciduous teeth, dental ankyloses, ectopic eruption.

Received: May 25, 2017; Accepted: June 09, 2017; Published: June 12, 2017 
may not exhibit a metallic sound or the loss of periodontal ligament space does not appear on radiographs [18]. A reliable sign of ankylosis has been dental infraocclusion that do not respond to orthodontic forces [18]. The ankylosed tooth does not follow the normal vertical growth of the alveolar process in a growing child, and a deficiency occurs, causing the tooth to be even more impacted [23].

The presence of ankylosed primary teeth may complicate eruption and development of the succedaneous permanent dentition [10], and it can lead to problems on occlusion [15], function, and esthetics [18]. When the exfoliation of affected teeth is delayed, complication such as deflected eruption paths for adjacent or opposing teeth, impaction of succedaneous teeth and depending on the degree of submergence of the ankylosed teeth, the position of the tooth germ may be affected, and hooked roots or impaction of permanent successors may occur $[10,25]$.

Rotated or poorly angulated premolars and a tooth directed horizontally or apically usually indicate a failure in normal root resorption of the primary molar [26]. The teeth that are not viable should be considered for extraction followed by orthodontic treatment regarding space management. Therefore, an early diagnosis and an effective treatment plan are fundamental to prevent further eruption deviations and more severe malocclusion $[10,15,27]$.

The article presents a case report with dentoalveolar ankylosis of the deciduous upper molar and impaction of the succeeding permanent teeth in which the patient was treated with extraction of the premolars and mesialization of the posterior segments using miniscrews.

\section{Diagnosis and etiology}

Patient female, was 15 years and 5 months, presented with a complaint about severely intruded maxillary left second deciduous molar and inclination of the adjacent tooth. The patient was referred to the orthodontist by maxillofacial surgeon, who found 2 impacted maxillary premolars (Figure 1) She had no oral habits or swallowing problems, normal functional movements, including movements of the temporomandibular joint, and family's medical history was noncontributory.

The facial analysis showed a balance face with lip seal at rest, a straight profile with a slight protrusion of the bottom lip (top lip, S-line, $0 \mathrm{~mm}$; bottom lip, S-line, $2 \mathrm{~mm}$ ) and an acceptable nasolabial angle. From a frontal view, there was a slight vertical excess of the lower third of the face. (Figure1)

The intraoral examination revealed an Angle Class III malocclusion, Class I canine relationship. The both maxillary second premolars were clinically absent, the second deciduous molars were retained, and the left second deciduous molar was severely intruded, suggestive of dentoalveolar ankylosis, the alveolar process in this region had a deficiency in vertical development, and the maxillary left first permanent molar was mildly inclined mesially. The overjet and overbite were 4.05 and $2.56 \mathrm{~mm}$, respectively, quadrangular-shaped arches, and no midline deviation. Arch-length deficiency was $0 \mathrm{~mm}$ in the maxilla and $-5 \mathrm{~mm}$ in the mandible. Oral hygiene is satisfactory. (Figure1,2).

Panoramic radiography revealed impacted maxillary second premolars close to the wall of the maxillary sinus, and they had a severely altered path of eruption. The upper and lower third molars could be observed (Figure 3). The cephalometric analysis demonstrated a skeletal Class I jaw relationship (ANB angle, $1.88^{\circ}$ ) with a hyperdivergent facial profile (SN-MP angle, $43.02^{\circ}$ ), linguoversion of the maxillary incisors

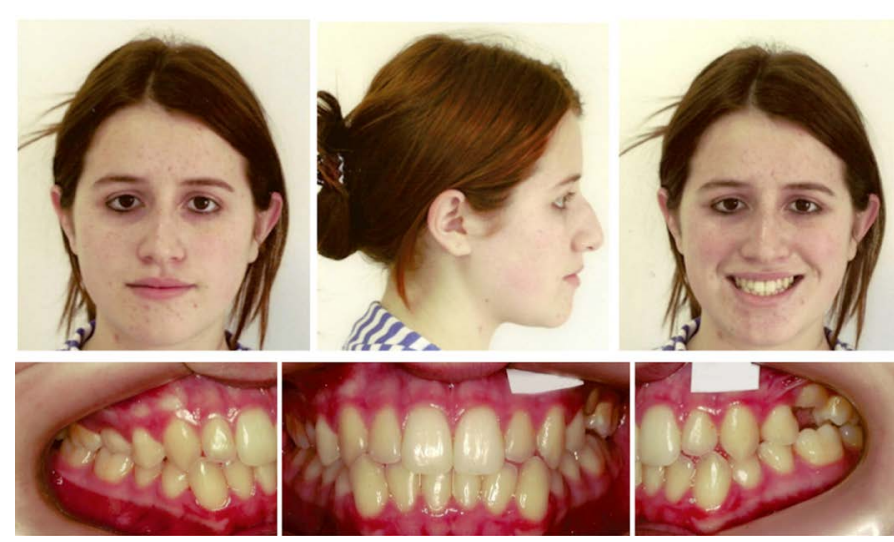

Figure 1. Extraoral and intraoral pretreatment photographs
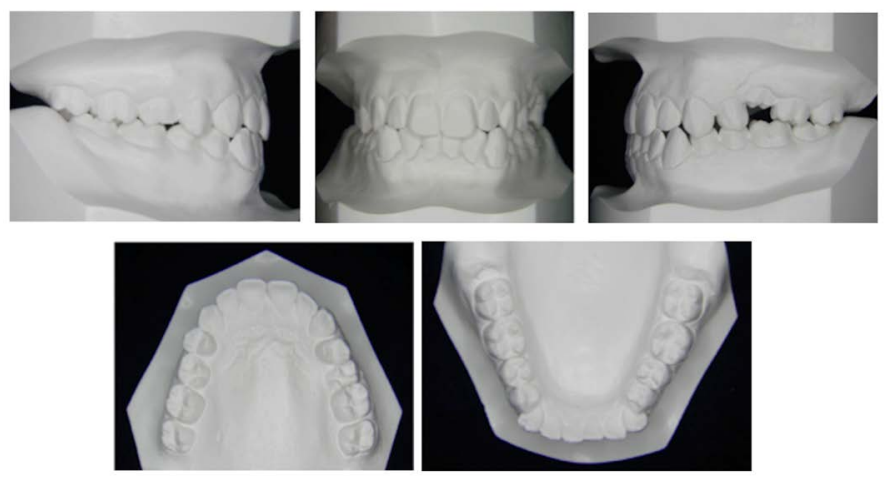

Figure 2. Pretreatment dental casts

(U1-SN angle, $98.95^{\circ}$ ), and linguoversion of the mandibular incisors (IMPA, $\left.80.73^{\circ}\right)$. The increased mandibular length (Co-Gn, $125.89 \mathrm{~mm}$; Co-A, 91,38mm), mandibular prognathism (Pog-Nperp, 8.33mm), and the linguoversion of the lower incisors confirmed a tendency for a Class III relationship (Figure 3).

The computed tomography (CT) was used to evaluate the location and orientation of impacted teeth and the possibility that the premolars were ankylosed and would not respond to the orthodontic force. The CT images showed a visible evidence of ankylosis of the both impacted second premolars and the left second deciduous molar making impossible the traction of the second premolars. The areas of ankylosis were observed on slices 38,40 and 42 (maxillary right second premolar) and on slices 86,88 and 90 (maxillary left second premolar) showing the absence of periodontal ligament continuity (Figure 4),(Table 1).

\section{Treatment objectives}

1. Maxilla: close the space after the extractions of ankylosed right second deciduous molar, retained left second deciduous molar, and impacted and ankylosed second premolars by the association of miniscrews to mesialize maxillary posterior teeth to avoid losing any anchorage and to control of the incisors vestibulolingual tipping, and the canine relationship during the space closure.

2. Mandible: maintain the maxillomandibular relationship during orthodontic treatment.

3. Occlusion: establish proper incisors and canine occlusion, obtain simultaneous bilateral contacts in harmony with centric relation, and disclude the posterior (canines guides) in mandibular excursive movements. 

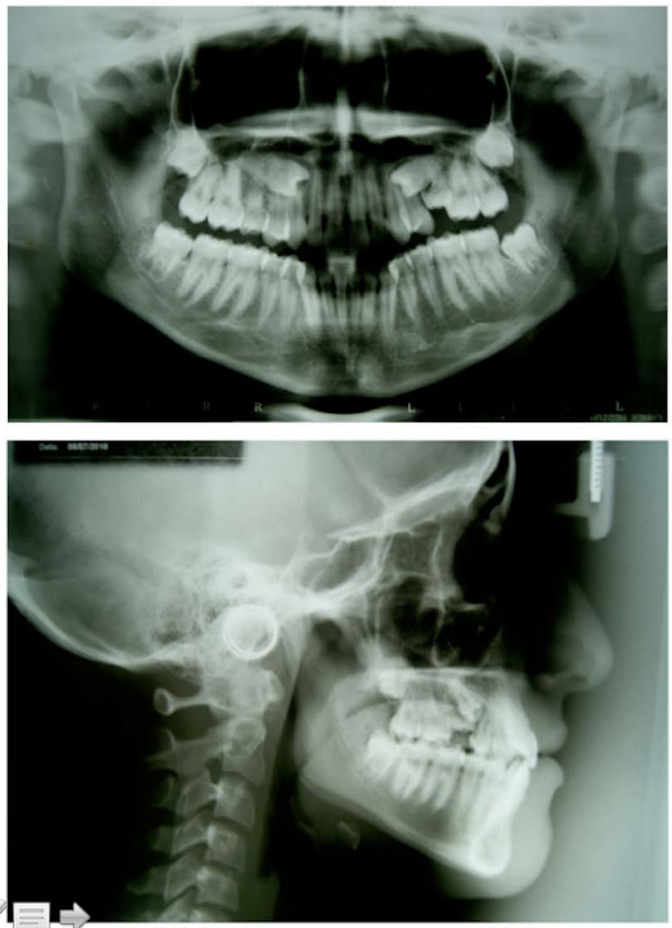

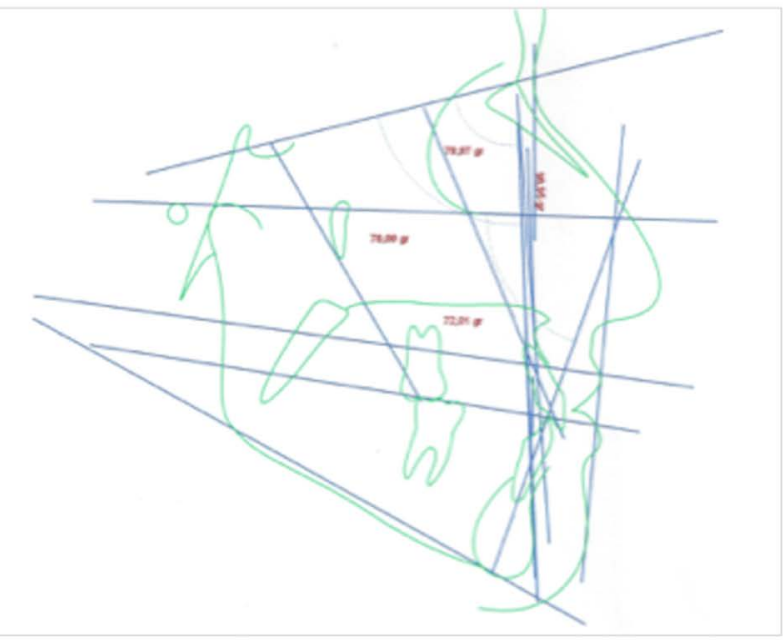

Figure 3. Pretreatment radiographs and cephalometric tracing
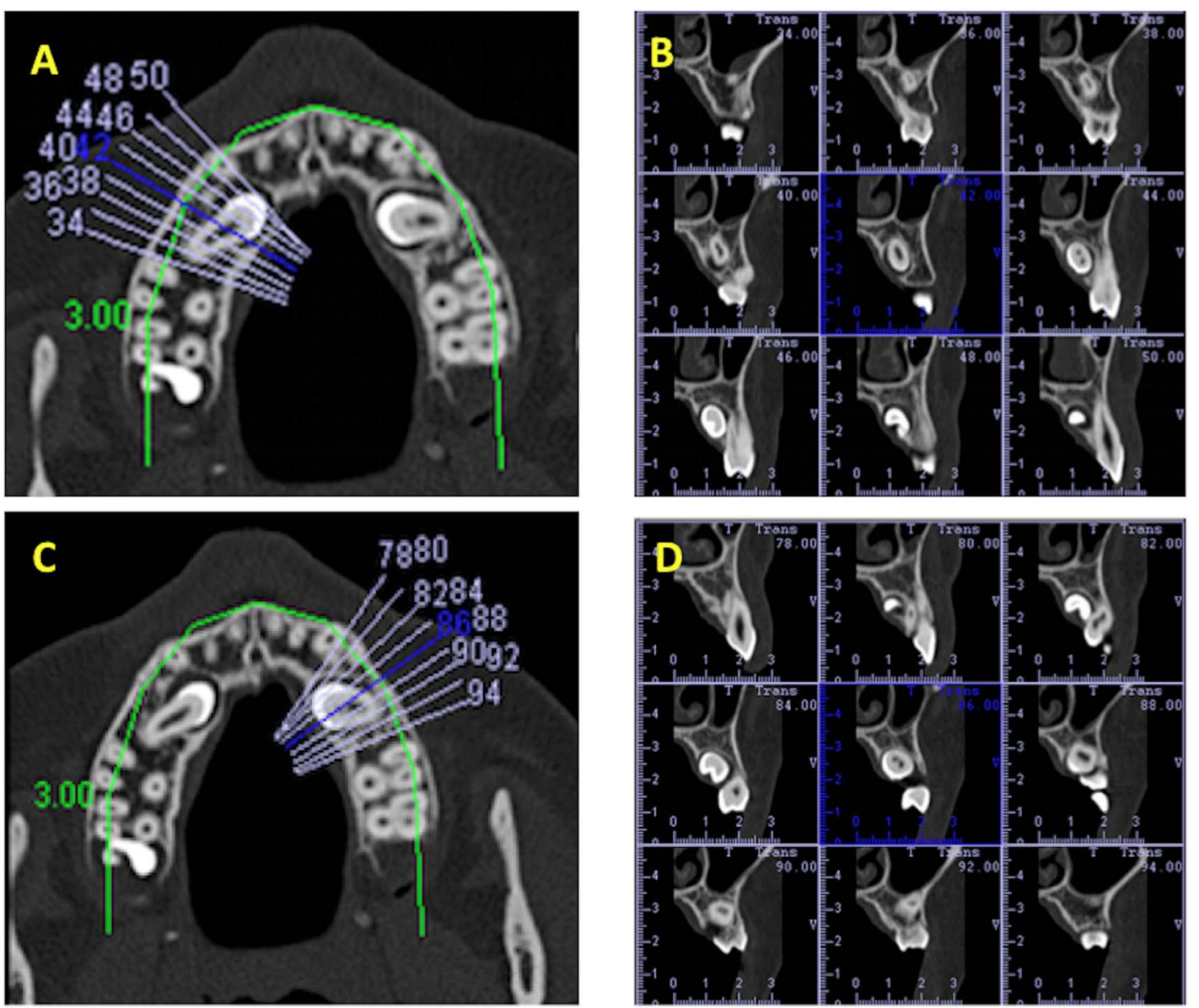

Figure 4. a \& b) Pretreatment parasagittal slices images of the CBCT on the right side. c \& d) Pretreatment parasagittal slices images of the CBCT on the left side. 
Table 1. Comparison of pretreatment and posttreatment cephalometric measurements.

\begin{tabular}{|c|c|c|}
\hline Measurement & Pretreatment & Posttreatment \\
\hline SNA $\left(^{\circ}\right)$ & 79.97 & 81.99 \\
\hline SNB $\left(^{\circ}\right)$ & 78.09 & 78.25 \\
\hline ANB $\left(^{\circ}\right)$ & 1.88 & 3.73 \\
\hline Mandibular body length (mm) & 125.89 & 128.57 \\
\hline Maxillar body length $(\mathrm{mm})$ & 91.38 & 93.98 \\
\hline Pog-Nperp & 8.33 & 0.52 \\
\hline SN-MP $\left(^{\circ}\right)$ & 43.02 & 39.86 \\
\hline U1-SN & 98.95 & 99.02 \\
\hline IMPA & $80.73^{\circ}$ & 88.09 \\
\hline Anterior facial height (mm) & 68.18 & 74.52 \\
\hline Top lip to Steiner' S-line (mm) & 0 & \\
\hline Bottom lip to Steiner' S-line (mm) & 2 & \\
\hline Overjet (mm) & 4.05 & 3.08 \\
\hline Overbite $(m m)$ & 2.56 & 2.34 \\
\hline
\end{tabular}

$S$, Sella; N, nasion; $A$, Point A; $B$, Point B; Go, gonion; $M e$, menton; Pog, pogonion; $M P$, mandibular plane; $U 1$, maxillary incisor; $I M P A$, incisor mandibular plane angle.

\section{Treatment alternatives}

There are 2 conventional treatment options for impacted teeth in adults: extraction or orthodontic relocation. The extraction of a severely impacted tooth tends to leave a periodontal defect at the adjacent tooth and its orthodontic relocation may benefit the surrounding structure by bringing the bone along as the tooth erupts [28]. The major concern in planning for this patient, besides the unfavorable position of the impacted teeth, was the possibility of ankylosis of the maxillary second premolars. Considering the CT diagnosis which confirmed the ankylosis, the treatment should be to extract the second premolars.

The use of the miniscrews was planned for mesialization of the posterior segments. It has settled as an important anchorage method for the control of the incisors and the canine relationship during the space closure.

The osseointegrated single-tooth implant would represent another option of treatment. However, the age of patient and inadequate bone could jeopardize long-term implant outcomes. Growth changes occur in the arches and result in adaptive changes in the teeth. These dental changes may result in a lack of occlusion vertically or malposition of adjacent natural teeth relative to the implant crown [29]. Furthermore, a more favorable occlusion would be obtained with the posterior segment mesialization considering her hyperdivergent facial profile.

\section{Treatment progress}

The patient was scheduled to install the orthodontic appliance and then to removal of the ankylosed deciduous second maxillary molars and the impacted and ankylosed second maxillary premolars. However, contrary to the recommendation, the patient had extractions before installing braces. For this reason, the orthodontic appliance had to be installed on the second week of extractions.

The patient was referred to an oral surgeon for extraction of the ankylosed maxillary left second deciduous molar, maxillary right second deciduous molar, and the impacted and ankylosed maxillary second premolars. At surgery, special attention was given to the preservation of the surrounding structures to allow bone thickness for the mesial movement of the posterior teeth (Figure 5).

Passive self-ligating brackets with $0.022 \times 0.028$-in slots were bonded to both arches. In the maxillary and mandibular arches, nitinol (NiTi) archwires, from 0.014 to $0.020 \mathrm{in}$, were used for alignment and leveling. In sequence, a rectangular section NiTi archwires of $0.019 \mathrm{X}$ 0.025-in were used for control the mesial movement of the posterior teeth by the association of orthodontic miniscrew. Two miniscrews (7.0 mm length and $1.8 \mathrm{~mm}$ diameter; Jeil Medical, Seoul, Korea) were placed between roots of the maxillary canines and first premolars on buccal. The super-elastic nickel titanium (NiTi) springs (closed coil springs) extending from the miniscrew to molar was used to move the posterior teeth mesially due to their consistent and constant force delivery (Figure 6). Class III elastics were used on the both sides for 7 months, to prevent mesial inclination of the canines and help control the incisors position. The first molar was completely mesialized after 23 months of traction.

As a result of the mesial movement of the molar, the bony defect caused by the impacted maxillary left second deciduous molar was resolved and normal alveolar bone height was restored. The infrabony defect caused by the impacted maxillary second premolars can be treated well with orthodontic movement (Figure 7).

Maxillary and mandibular rectangular arches of 0.019 X 0.025 in were used to finalize the tooth positions. The brackets, bands and the miniscrews were removed after 37 months of treatment. After the active treatment phase, a removable maxillary Hawley retainer and a mandibular lingual bonded retainer were used to maintain the tooth positions.

\section{Treatment results}

The posttreatment records show a satisfactory treatment result (Figure 7-9).

1. Maxilla: Extraction of the second permanent premolars was necessary because they were ankylosed. There was control of
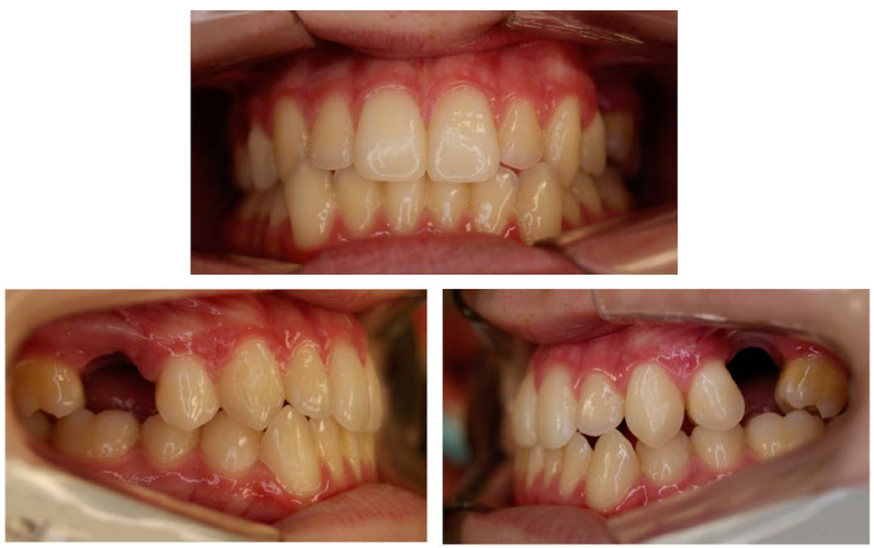

Figure 5. Intraoral photographs after surgery.
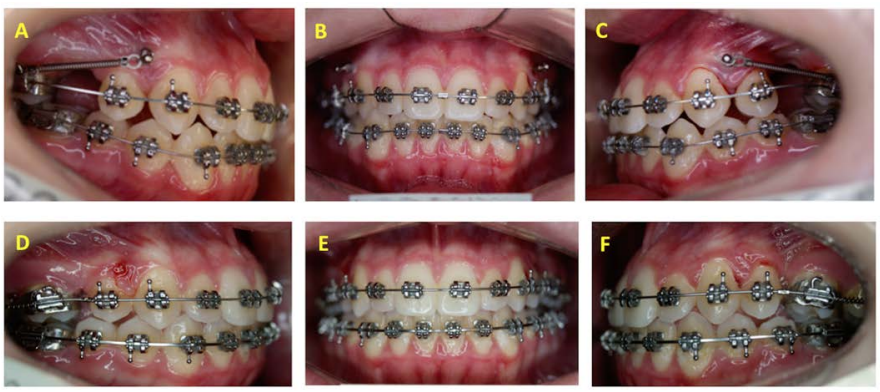

Figure 6. (a, b, c, d, e \& f) Progress intraoral photographs. Miniscrews were placed between roots of the maxillary canines and first premolars and used to move the maxillary posterior teeth mesially. 

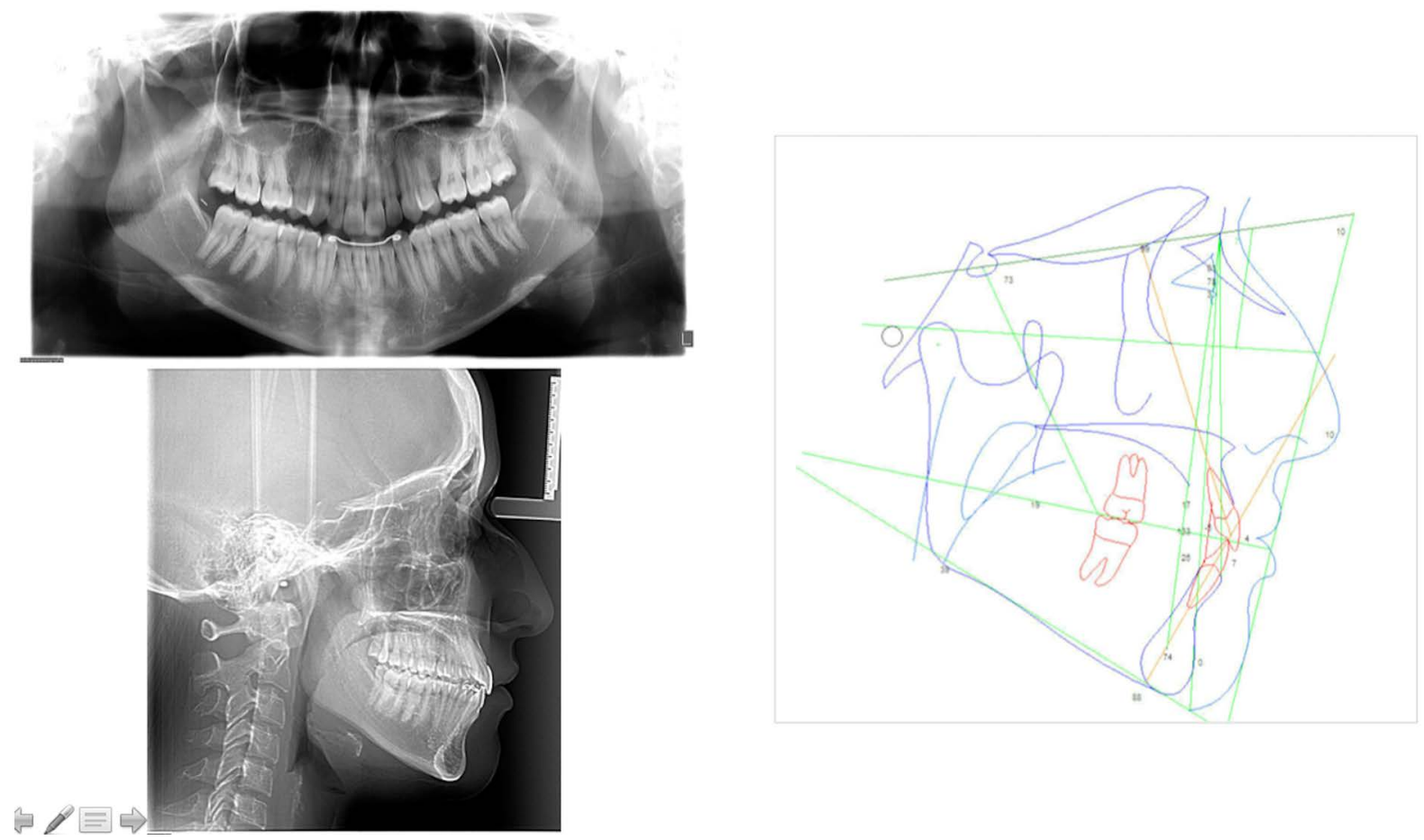

Figure 7. Posttreatment radiographs and cephalometric tracing

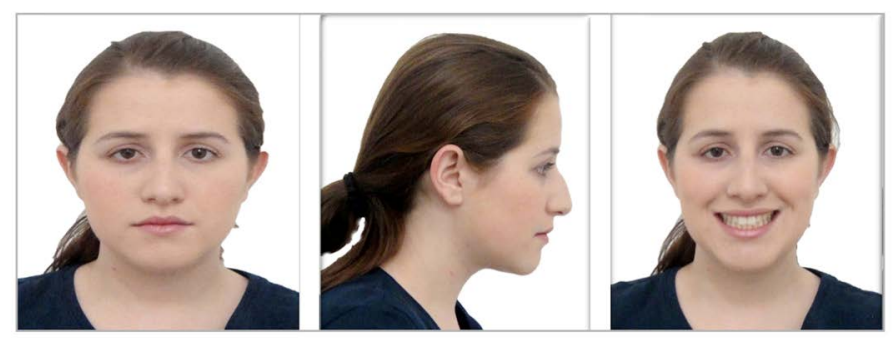

Figure 8. Extrabucal posttreatment photographs
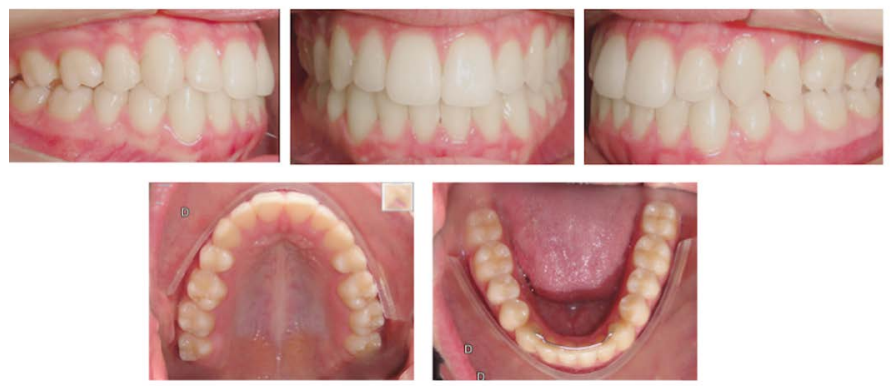

Figure 9. Intraoral posttreatment photographs

the anchorage during mesialization of the posterior teeth using miniscrews. Its vertical and transverse positioning was maintained.

2. Mandible: adequate overjet and overbite, since the patient had a straight profile. The vertical, anteroposterior, and transverse positions were maintained.

3. Occlusion: in the maxillary arch, the first molars were positioned in the place of the second premolars. The occlusal posttreatment evaluation revealed a Class II molar and Class I canine relationship on both sides, normal overjet and overbite, and good intercuspation. Ideal functional occlusion was obtained.

4. Panoramic radiography revealed good positioning and good periodontal health of the teeth, and the parallax of the roots of the teeth. The radiograph showed acceptable alveolar bone height between the maxillary left first premolar and the first molar with a cortical bone layer, and the roots were well aligned with no significant root resorption (Figure 10).

5. Facial esthetics: the patient's skeletal pattern was not altered by the mechanics and the facial esthetics was not compromised. (top lip, $\mathrm{S}$-line $=0 \mathrm{~mm}$; bottom lip, S-line $=2 \mathrm{~mm}$ ).

The mean duration of treatment was 37 months. Results that are finalization in Class II relationship without changing the patient's pattern as well as the overjet and the overbite.

\section{Discussions}

The process of eruption in the human dentition is complex and poorly understood [30]. The ankylosis of the permanent tooth often impedes the normal development of teeth [27]. Different treatments have been related for the management of tooth ankylosis, which depends upon whether it is a deciduous or permanent tooth, the extent of ankylosis, the time of diagnosis and the location of the affected tooth31. Studies [32-35] related that initially root resorption is delayed in infraoccluded molars, however, it turns out to be came regular and the exfoliation occurs normally. Kurol et al. moreover describe a normal exfoliation of infraoccluded primary molars and that alveolar bone achieve a normal height during permanent teeth eruption [24,36-39]. Extraction of the ankylosed deciduous tooth and space management may be indicated in cases of advanced disruption to the occlusion and/ or the underlying premolar, severe infraocclusion, and abnormal root resorption due to mesial or distal location of the permanent successor and severe tipping of the adjacent teeth $[2,40,41]$. 

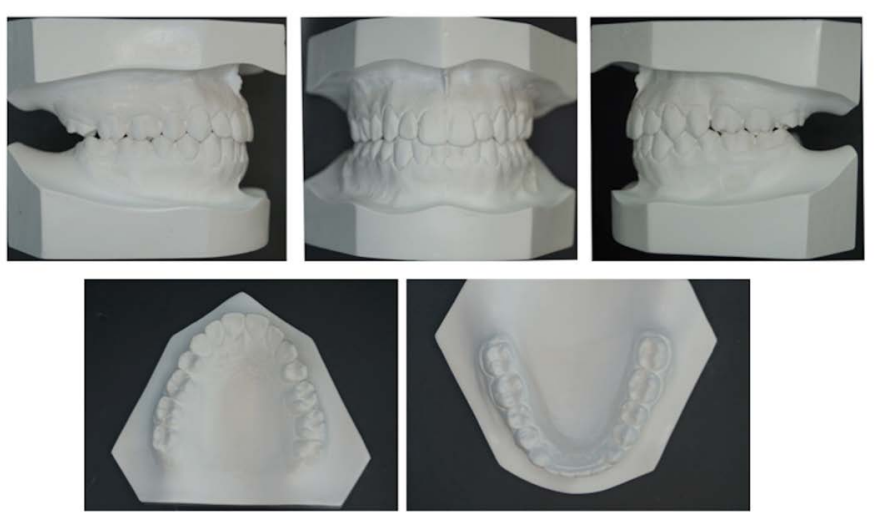

Figure 10. Posttreatment dental casts

According to Becker and Karnei-R'em [42], a local change of the transseptal fibers, which are reoriented diagonally downward in the direction to the infraoccluded ankylosed tooth could be observed in young people with infraoccluded deciduous teeth, over many years, and could explain the mesial tipping of the first permanent molar to the ankylosed tooth. Other authors [14] also associate increased susceptibility to periodontal breakdown, with lack of alveolar bone height and formation of periodontal pockets, especially when the ankylosed tooth was retained for a long time or when extraction was needed [15].

Impacted teeth are more often ankylosed in adults [43]. Once the tooth is not accessible to clinical examination, its diagnosis poses difficulties and it has been considered challenging for clinicians. The prognosis of treatment depends on the position of the impacted tooth in relation to the adjacent teeth and their height in the alveolar process. One should also consider the possibility that the impacted tooth could be ankylosed then it will not move orthodontically. The computed tomographic exam is fundamental in establishing effective therapeutic procedures for the patient, as well as for minimizing all alterations that are possibly associated with the impactation or ankylosis of the tooth in the occlusion. The conventional radiographic examination is considered to be of limited value in the detection of ankylosis [44] for the reason that of 2-dimensional nature of the image complicating detection of the ankylosed areas on the labial or lingual root surfaces [45]. These limitations can be overcome by the use of computerized tomography (CT). CT has been considered the examination of choice in this case, since it provides high-resolution imaging, diagnostic reliability, and risk-benefit assessment [46]. Multislice computed tomography was reported to be superior to cone-beam computed tomography for the visualization of the periodontal ligament space $[47,48]$. However, it also cannot reliably detect the focal area of ankylosis due to factors such as slice thickness [49]. Therefore, there is even a possibility the tooth not to respond to the orthodontic force and the impacted tooth should be monitored during its attempted traction.

The ankylosis and the impaction of the permanent successor tooth may result from malocclusion disturbances of the primary dentition, and the ankylosis makes impossible any mechanism trying guidance eruption. Unfortunately, limitations such as the position of the impacted tooth, ankylosis, dental and skeletal age, teeth involved (periodontal status, tooth shape and size), and the need for compensatory reshaping of teeth [50] could pose problems especially in the late diagnosis. Therefore, as suggested by Kurol [27], an early diagnosis to intervene at the ideal moment and an effective treatment plan to intercept the problem are fundamental to prevent further eruption deviations and more severe malocclusion. In this case, the impaction of the maxillary second premolar may be associated with over-retained and infraocclusal ankylosed deciduous molar.

Becker and Shochat [51] showed that extraction of an ankylosed tooth allows for recovery of the eruption process of the developing permanent successor and the development of normal root length. In some situations, however, altered morphology and the possibility of dental rotation intrabony make it difficult to management of the space [14].

In this case report, the permanent successor has an altered path of eruption, occlusal disturbance, alveolar bone defects, and the ankylosed primary molar was severely infraoccluded with the adjacent teeth tipping. Infraocclusion of primary molars occurs commonly in mixed dentition, an easily detected clinical alteration which indicates a modification of the eruptive process, a disruption of the alveolar growth, and it is also an indication to possible eruptive disruption of the corresponding premolars [2]. In this situation, early interceptive orthodontic treatment is recommended [10,27] and the extractions was decided in order to allow the closure of the space through the mesialization of the maxillary posterior teeth, to promote more favorable result as possible and allow the bone tissue to adapt better, thus ensuring periodontal and dental stability.

With the advent of orthodontic miniscrews, many situations that were previously difficult to resolve have become real possibilities. With these mechanics, mesial movement of the posterior teeth was achieved without retroclination of the maxillary incisors, which would have been unfavorable in this patient, because of her facial profile, and for maintaining the working excursion of the mandible in canines guides.

In this case, a late diagnosis of dentoalveolar ankylosis of a deciduous tooth may have aggravated the disorder of the eruptive process of the successor tooth, as well as the development of the bone involved and it is in agreement with Krakowiak [52] and Naizf [53] who suggested there can be a modification in premolars development associated with infraoccluded molars. Furthermore, the position and the ankylosis of the impacted permanent tooth, and the periodontal status created difficulties and limitations to the treatment plan. Studies $[22,54]$ state there is a delay in exfoliation of infraoccluded primary molars, however, Nafiz et al. found significant results in root resorption delay for first primary molars, but not for second primary molars, it could explain the delay in infraocclusion manifestation in second primary molars. Therefore, conditions predisposing to malocclusion, as infraocclusion of the deciduous tooth that may be associated with development of the permanent successor, should be identified as soon as possible. Early diagnosis avoids later complications; for that reason clinicians should consider clinical, radiological and histological conditions.

\section{Conclusion}

It is important to diagnose the dental ankyloses or impaction problems as early as possible in order to treatment planning achieve better results along stability, and for unerupted tooth is detected and analyze its anatomy, eruptive potential and spatial orientation.

The complementary exams such as radiographic or CT are imperative for evaluate de condition of the teeth such as ankyloses or impaction due to disturbed tooth eruption.

\section{Acknowledgements}

There were not any organizations that funded my manuscript. It was funded by ourselves.

There is no conflict of interest on this paper. 


\section{References}

1. Cappellette M, Cappellette Jr M, Fernandes LCM, Oliveira APO, Yamamoto LH, et al. (2008) Caninos permanentes retidos por palatino: diagnóstico e terapêutica - uma sugestão técnica de tratamento. R Dental Press Ortodon Ortop Facial. 1: 60-73.

2. Raju AS, Reddy VP, Hegde N, Chandrashekar BS, Vani J, et al. (2012) Eruptive Abnormalities: An Interdisciplinary Approach. International Journal of Health Sciences \& Research 2: 133-142.

3. McNamara C, McNamara TG (2005) Mandibular premolar impaction: 2 case reports. $J$ Can Dent Assoc 71: 859-863. [Crossref]

4. Andreasen JO (1997) The impacted premolar. In: Andreasen, J.O.; Petersen, J.K.; Laskin, D.M.; editors. Textbook and color atlas of tooth impactions; diagnosis, treatment and prevention. Copenhagen: Munksgaard. 177-195.

5. Ezirganli S, Kirtay M, Ozer K, Un EC, Kosger HH, et al. (2013) The Prevalence of Impacted Premolars in the Anatolian Population. Bezmialem Science.1: 28-32.

6. Hashim HA, Al-Qahtani A, Taha SM, Tharupeedikayil S, Ahmed MF (2013) Management of complete impacted maxillary second deciduous molar with the aid of cone beam computed tomography: case report and a review of the literature. $J$ Orthod Sci 4: 130-135. [Crossref]

7. Yildirim-Oz G, Tosun G, Kiziloglu D, DurmuÅŸ E, Sener Y (2007) An unusual association of odontomas with primary teeth. Eur J Dent 1: 45-49. [Crossref]

8. Dolanmaz D, Karaman AI, Pampu AA, Topkara A (2010) Orthodontic treatment of an ankylosed maxillary central incisor through osteogenic distraction. Angle Orthod 80: 391-395. [Crossref]

9. Biederman W (1962) Etiology and treatment of tooth ankylosis. Am J Orthod 48: 670684.

10. Tieu LD, Walker SL, Major MP, Flores-Mir C (2013) Management of ankylosed primary molars with premolar successors: a systematic review. J Am Dent Assoc 144: 602-611. [Crossref]

11. Panos P (2003) Tooth ankylosis: Orthodontic implications. Hel Orthod Rev 6: 75-88.

12. Sidhu HK, Ali A (2001) Hypodontia, ankylosis and infraocclusion: report of a case restored with a fibre-reinforced ceromeric bridge. $B r$ Dent $J$ 11: 613-616. [Crossref]

13. Salem K, Mirzaee B (2009) Infaocclusion of primary molars and associated dental anomalies.Research Journal of Biological Sciences 4: 1217-1220.

14. Messer LB, Cline JT (1980) Ankylosed primary molars: results and treatment recommendations from an eight-year longitudinal study. Pediatr Dent 2: 37-47.

15. Loriato LB, Machado AW, Souki BQ, Pereira TJ (2009) Late diagnosis of dentoalveola ankylosis: impact on effectiveness and efficiency of orthodontic treatment. Am J Orthod Dentofacial Orthop 135: 799-808. [Crossref]

16. Guimarães CH, Henriques JC, Janson G, Moura WS (2015) Stability of interceptive/ corrective orthodontic treatment for tooth ankylosis and Class II mandibular deficiency: A case report with 10 years follow-up. Indian J Dent Res 26: 315-9. [Crossref]

17. Gündüz K, Muğlali M, Inal S (2007) Total impaction of deciduous maxillary molars: two case reports. J Contemp Dent Pract 8: 64-71. [Crossref]

18. Lim WH, Kim HJ, Chun YS (2008) Treatment of ankylosed mandibular first permanen molar. Am J Orthod Dentofacial Orthop 133: 95-101. [Crossref]

19. Tieu LD, Walker SL, Major MP, Flores-Mir C (2013) Management of ankylosed primary molars with premolar successors: a systematic review. J Am Dent Assoc 144: 602-611. [Crossref]

20. Ustad F, Alaajam WH, Ali FM, AlShahrani I (2014) Impacted primary tooth: A case report. Int J Res Health Sci [Internet] 2: 356-8.

21. Suprabha BS, Pai SM (2006) Ankylosis of primary molar along with congenitally missing first permanent molar. J Indian Soc Pedod Prev Dent 24 Suppl 1: S35-37. [Crossref]

22. Silva CC, Edo MM, Llorente MSA, Leache EB (2014) Primary molar infraocclusion: frequency, magnitude, root resorption and premolar agenesis in a Spanish sample. European journal of Paediatric Dentistry 15: 258-264.

23. Kofod T, Würtz V, Melsen B (2005) Treatment of an ankylosed central incisor by single tooth dento-osseous osteotomy and a simple distraction device. Am J Orthod Dentofacial Orthop 127: 72-80. [Crossref]

24. Kurol J, Magnusson BC (1984) Infraocclusion of primary molars: a histologic study. Scand J Dent Res 92: 564-576. [Crossref]
25. Miyanaga M, Takei K, Maeda T (1998) Observation of a child with multiple submerged primary teeth. ASDC J Dent Child 65: 495-498, 439. [Crossref]

26. Burch J, Ngan P, Hackman A (1994) Diagnosis and treatment planning for unerupted premolars. Pediatr Dent 16: 89-95. [Crossref]

27. Kurol J (2002) Early treatment of tooth-eruption disturbances. Am J Orthod Dentofacial Orthop 121: 588-591. [Crossref]

28. Goudy S, Lott D, Burton R, Wheeler J, Canady J (2009) Secondary Alveolar Bone Grafting: Outcomes, Revisions, and New Applications. Cleft Palate Craniofac J 46: 610-612.

29. Oesterle LJ, Cronin RJ Jr (2000) Adult growth, aging, and the single-tooth implant. Int J Oral Maxillofac Implants 15: 252-260. [Crossref]

30. Rhoads SG, Heather M, Hendricks HM, Frazier-Bowers SA (2013) Establishing the diagnostic criteria for eruption disorders based on genetic and clinical data. Am J Orthod Dentofacial Orthop 144: 194-202. [Crossref]

31. McNamara TG, O'Shea D, McNamara CM, Foley TF (2000) The management of traumatic ankylosis during orthodontics: a case report. $J$ Clin Pediatr Dent 24: 265 267. [Crossref]

32. Amir E, Duperon DF (1982) Unerupted second primary molar. ASDC J Dent Child 49 365-368. [Crossref]

33. Brearley LJ, McKibben DH Jr (1973) Ankylosis of primary molar teeth. I. Prevalence and characteristics. ASDC J Dent Child 40: 54-63. [Crossref]

34. Koyoumdjisky-Kaye E, Steigman S (1982) Ethnic variability in the prevalence of submerged primary molars. $J$ Dent Res 61: 1401-1404. [Crossref]

35. Koyoumdjisky-Kaye E, Steigman S (1982) Submerging primary molars in Israeli rural children. Community Dent Oral Epidemiol 10: 204-208. [Crossref]

36. Kurol J, Thilander B (1984) Infraocclusion of primary molars and the effect on occlusal development, a longitudinal study. Eur J Orthod 6: 277-293. [Crossref]

37. Kurol J, Thilander B (1984) Infraocclusion of primary molars with aplasia of the permanent successor. A longitudinal study. Angle Orthod 54: 283-294. [Crossref]

38. Kurol J (1981) Infraocclusion of primary molars: an epidemiologic and familial study. Community Dent Oral Epidemiol 9: 94-102. [Crossref]

39. Kurol J, Olson L (1991) Ankylosis of primary molars--a future periodontal threat to the first permanent molars? Eur J Orthod 13: 404-409. [Crossref]

40. Achi-Beaini B, Skaf Z (2001) Secondary retention of primary molars. Diagnosis and treatment. Dental News 11: 25-8.

41. Kennedy DB (2009) Treatment strategies for ankylosed primary molars. Eur Arch Paediatr Dent 10(4): 201-10. [Crossref]

42. Becker A, Karnei-R'em RM (1992) The effects of infraocclusion: Part 1. Tilting of the adjacent teeth and local space loss. Am J Orthod Dentofacial Orthop 102: 256-264. [Crossref]

43. Kim SJ, Kim JW, Choi TH, Lee KJ (2015) Restoration of a vertical alveolar bone defect by orthodontic relocation of a mesially impacted mandibular first molar. $\mathrm{Am} \mathrm{J}$ Orthod Dentofacial Orthop 147: S122-32. [Crossref]

44. Campbell KM, Casas MJ, Kenny DJ (2005) Ankylosis of Traumatized Permanent Incisors: Pathogenesis and Current Approaches to Diagnosis and Management. JCDA 71: 763-68. [Crossref]

45. Andersson L (1988) Dentoalveolar ankylosis and associated root resorption in replanted teeth. Experimental and clinical studies in monkeys and man. Swed Dent J Suppl 56 1-75. [Crossref]

46. Silva MAG, Wolf U, Heinicke F, Bumann A, Visser H, et al. (2008) Cone-beam computed tomography for routine orthodontic treatment planning: A radiation dose evaluation. Am J Orthod Dentofacial Orthop 133: 640.e1-640.e5. [Crossref]

47. Holberg C, Steinhäuser S, Geis P, Rudzki-Janson I (2005) Cone-beam computed tomography in orthodontics: benefits and limitations. J Orofac Orthop 66: 434-444. [Crossref]

48. Paris M, Trunde F, Bossard D, Farges JC, Coudert JL (2010) [Dental ankylosis diagnosed by $\mathrm{CT}$ with tridimensional reconstructions]. J Radiol 91: 707-711. [Crossref]

49. Hirabayashi S, Umamoto N, Tachi M, Sugawara Y, Sakurai A, et al. (2001) Optimized 3-D CT scan protocol for longitudinal morphological estimation in craniofacial surgery. J Craniofac Surg 12: 136-140. [Crossref] 
50. Sapir S, Shapira J (2008) Decoronation for the management of an ankylosed young permanent tooth. Dent Traumatol 24: 131-135. [Crossref]

51. Becker A, Shochat S (1982) Submergence of a deciduous tooth: its ramifications on the dentition and treatment of the resulting malocclusion. Am J Orthod 81: 240-244. [Crossref]

52. Krakowiak FJ (1978) Ankylosed primary molars. ASDC J Dent Child 45: 288-292. [Crossref]
53. Nazif MM, Zullo T, Paulette S (1986) The effects of primary molar ankylosis on root resorption and the development of permanent successors. ASDC J Dent Child 53: 115118. [Crossref]

54. de-la-Rosa-Gay C, Valmaseda-Castellón E, Costa-Codina X, Gay-Escoda C (1998) Infraclusion of primary molars: reports of cases. ASDC J Dent Child 65: 47-51. [Crossref]

Copyright: $\bigcirc 2017$ Cappellette M. This is an open-access article distributed under the terms of the Creative Commons Attribution License, which permits unrestricted use, distribution, and reproduction in any medium, provided the original author and source are credited. 